\title{
Knowledge, Attitude and Practice of Self Medication among Pharmacy Students of Rift Valley University, Abichu Campus, Addis Ababa, Ethiopia
}

Alemseged Beyene ${ }^{1}$, Edomgenet Getachew ${ }^{2}$, Askalech Doboch ${ }^{2}$, Estifanos Poulos ${ }^{2}$, Kedija Abdurahman ${ }^{2}$ and Minyahil Alebachew ${ }^{1 *}$

${ }^{1}$ Department of Pharmacology and Clinical Pharmacy, College of Health Sciences, Addis Ababa University, Addis Ababa, Ethiopia

${ }^{2}$ Department of Pharmacy, Rift Valley University, Abichu Campus, Addis Ababa, Ethiopia

\begin{abstract}
Introduction: Now a day's self-medication practice is increasing widely due to availability of variety of over the counter medications. Self-medication practice is expected to be higher in health science students due to their exposure to knowledge about different diseases and drugs. If self-medication is used properly it saves time and money spent. Improper self-medication practice or medication abuse may lead to serious adverse drug reactions and possibly fatal consequences and emergence of antibiotic resistant.
\end{abstract}

Objective: The aim of this study is to assess the knowledge, attitude and practice of self-medication among Pharmacy Students in Rift Valley University of the Abichu campus.

Methods: A cross sectional survey was conducted using self-administered questionnaires which comprise 7 parts among pharmacy students (year one to five) who were available during the study period (January $1^{\text {st }}$ to February $1^{\text {st }}$ 2017). Descriptive statistics was used to describe the frequency of variables contained in the questionnaire.

Results: Six hundred forty students were included in the study, of these 443 students were participated. A total of 400 students filled properly and returned the questionnaire. Among the participants, $218(54.5 \%)$ were females with the prevalent age group of 26-35 years $202(50.2 \%)$. Nearly half of the respondents $189(47.3 \%)$ didn't know the medication classification of OTC and prescription only drugs. About $165(41.3 \%)$ had information about the medication classification of OTC and prescription only drugs. The most frequently reported self-medication symptom was fever/ headache $(69.3 \%)$ followed by gastric pain $(67.5 \%)$. The three main reasons for self-medication were non-seriousness, quick relief and emergency use accounting for $81.3 \%, 70.3 \%$, and $45.8 \%$ respectively. Among the respondents, 109 $(27.3 \%)$ had not practiced self-medication. $262(65.5 \%)$ had visited physicians for the illnesses encountered whereas $52(13.0 \%)$ had taken no action and others $291(72.8)$ used pure self-medication from pharmacy or drug vendor without prescription. Paracetamol $(92.0 \%)$, antacids $(71.8 \%)$ and antibiotic $(66.8 \%)$ were the most frequently consumed medication among the participants. The main source of information during self-medication was reading material $(56.3 \%)$ followed by advice from pharmacist (43.8\%), and advice from physician/nurses without prescription (38.8\%). More than half of the respondents agreed that the practice of self-medication is part of self-care in the study.

Conclusion and Recommendation: A significant number of students were identified to practice self-medication and nearly half of the respondents have no knowledge about OTC and prescriptions only drugs. Prevalence of selfmedication increases as year of study increases. This may be due to increased study exposure to diseases and medications. Students should be aware that improper use of medications can lead to drug resistance, toxicity, and increased side effects.

Keywords: Self-medication; Rift valley; Toxicity

\section{Introduction}

Self-medication can be defined as obtaining and consuming one (or more) drug (s) without the advice of a physician either for diagnosis, prescription or surveillance of the treatment [1]. This includes acquiring medicines without a prescription, resubmitting old prescriptions to purchase medicines, sharing medicines with relatives or members of one's social circle or using leftover medicines stored at home and It is an issue with serious global implications [2]. The International Pharmaceutical Federation (FIP) defines self-medication as the use of non-prescription medicines by people on their own initiative [3]. As per the WHO 'Self-medication is the selection and use of medicines by individuals to treat self-recognized illnesses or symptoms [4].

Self-medication behaviour varies significantly with a number of socio-economic characteristics [5]. Some of them are educational level which means when they have poor knowledge or unspecialized knowledge in health education and when they are not in educational level which lack medical information. Other socioeconomic status, access to medical information, awareness about health, exposure to advertisements and perception of illnesses, accessibility to medicine and health care facilities, and health sector reforms among others. Improvement in peoples' general knowledge, level of education, socioeconomic status, and development of new technologies (e.g. internet and related communication) is promoting self-medication worldwide [6].

Responsible self-medication has been advocated by the World Health Organization (WHO) for the treatment and prevention of condition/symptoms that do not require medical consultation [7].

*Corresponding author: Minyahil Alebachew, Department of Pharmacology and Clinical Pharmacy, School of Pharmacy, College of Health Sciences, Addis Ababa University, Addis Ababa, Ethiopia, Tel: +251-912-648527; E-mail: minwoldu@gmail.com, minyahil.alebachew@aau.edu.et

Received June 23, 2017; Accepted June 29, 2017; Published July 05, 2017

Citation: Beyene A, Getachew E, Doboch A, Poulos E, Abdurahman K, et al. (2017) Knowledge, Attitude and Practice of Self Medication among Pharmacy Students of Rift Valley University, Abichu Campus, Addis Ababa, Ethiopia. J Health Med Informat 8: 269. doi: 10.4172/2157-7420.1000269

Copyright: @ 2017 Beyene A, et al. This is an open-access article distributed under the terms of the Creative Commons Attribution License, which permits unrestricted use, distribution, and reproduction in any medium, provided the original author and source are credited. 
Citation: Beyene A, Getachew E, Doboch A, Poulos E, Abdurahman K, et al. (2017) Knowledge, Attitude and Practice of Self Medication among Pharmacy Students of Rift Valley University, Abichu Campus, Addis Ababa, Ethiopia. J Health Med Informat 8: 269. doi: 10.4172/21577420.1000269

Page 2 of 6

It is a cheaper alternative for treating common illnesses and may be important in developing countries where access to medical services are difficult and there is a shortage of medical personnel especially in rural areas. However, the practice of self-medication should be supported by unbiased medical information provided to patients to avoid health hazards $[8]$.

Self-medication has both benefits and risks, proper use of selfmedication can save scarce medical resources from being wasted on minor conditions, reduce the burden on health care facilities, and decrease the cost and time people spend to visit health care facilities for minor symptoms [9]. However, inappropriate self-medication can have a number of potential risks for example delay in seeking appropriate medical advice; failure to recognize or self-diagnose contraindications, interactions with prescribed medicinal products; failure to report current self-medications to the prescribing physician (risk of double medication and/or harmful interaction) inappropriate duration of use of medicine; risk of dependence and abuse etc. [6,10]. Studies have shown that self-medication patterns vary among different populations. It has been also shown that self-medication is much more common among physicians, nurse, pharmacists and medical students than among the general population [4].

Physicians and pharmacists are considered to be the worst offenders as they have an easy access to medications and the knowledge use it at any whenever needed $[11,12]$. Self-medication assumes a special significance among the medical students as they are the future medical practitioners and have a potential role in counselling the patients about the advantages and disadvantages of self-medication. Medical students also differ from the general population because they are well-exposed to the knowledge about diseases and drugs [13].

In Ethiopia, almost every pharmacy sells drugs without a prescription; a phenomenon seen in many developing countries consequently, antibiotics and potentially habit forming medicines such as Dextromethorphan, Tramadol and others are easily available to the common man. This together with poor awareness leaves the layman uninformed about the potentially lethal effects of some of these drugs. Also, the lack of a good primary health care system coupled with cost issues causes the general public to approach various other doors instead of a doctor's to seek help for a problem. Despite this, there is paucity of literature regarding self-medication in Ethiopia and no measures have been taken to address this problem. This study presents to know the results of University pharmacy student knowledge, attitude, and practice towards self-medication [2]. Therefore, the present study assesses the Knowledge, Attitude and Practice (KAP) of Self-Medication among Pharmacy Students in Rift Valley University, Abichu campus, Addis Ababa, Ethiopia.

\section{Methods}

\section{Study area and period}

The study was conducted in Rift Valley University Abicho campus from January $1^{\text {st }}$ to February $1^{\text {st }}, 2017$. The campus is located around "Meganagna" Adiss Ababa. Rift Valley University was established in Sept 2007 and it is the largest private university with different campus around the country and it is also an educational center for different programs.

\section{Study design}

A cross-sectional survey study was conducted by using a selfadministered questionnaire.

\section{Source and study population}

Source population: All students of Rift Valley University of Abicho campus were a source population.

Study population: All pharmacy students were enrolled to the study.

\section{Inclusion and exclusion criteria}

All pharmacy students from year one to year five were included. Pharmacy students who were not available during the study period and who were not volunteers to participate were excluded.

\section{Data management system}

Data collectors: The self-administered questionnaires were distributed and collected by the investigators from the students' class rooms, after explanation regarding the study purpose and impact.

Data collection tool: Questionnaires prepared in English which consists of 7 parts were distributed to collect all relevant data. No data was requested from the questionnaire that could lead to the identification of the participants. Contents of the questionnaires include; demographic information's which includes sex, age, year of study and school, the second part consists of disease or symptoms frequently self- treated, measures taken for the illness, source of information for self-medication and finally attitude of the students towards self-medications. Descriptive statistics was used to describe the frequency of variables contained in the questioner.

Sampling: Convenient sampling technique was used because we took all pharmacy students. Total number of pharmacy students were 640 and 443 students were available during study period and filled the questionnaire. Among the participants 400 were filled properly, completely and returned the questionnaire.

Data analysis: Data was analysed using SPSS version 21. A descriptive statistics was used to describe demographic information as well as variables contained in the questioner in order to assess practice, attitude and knowledge of self-medication practice among pharmacy students. The results were presented in the form of tables, texts, figures.

\section{Variables}

Dependent variables: Attitude towards self-medication, Practice of self-medication, knowledge about medication classification.

Independent variables: Age, sex, years of pharmacy students, previous treatment the same diseases or symptoms, family and peer pressure, availability of drugs, cost of medication, lack of time, severity of disease or symptoms, type of drugs.

\section{Ethical issues}

To obtain the consent of students prior to data collection, a detailed explanation on the aim and objectives of the study was given. They were also informed that participation is voluntary and confidentiality would be maintained throughout the study.

\section{Results}

\section{Demographic information}

A total of 443 questionnaires were distributed to be filled by respondents, 400 were filled completely and collected, which gives the response rate of $90.2 \%$. Moreover, 43 (10.75\%) of the questionnaires were rejected because of incomplete information. The study was 
Citation: Beyene A, Getachew E, Doboch A, Poulos E, Abdurahman K, et al. (2017) Knowledge, Attitude and Practice of Self Medication among Pharmacy Students of Rift Valley University, Abichu Campus, Addis Ababa, Ethiopia. J Health Med Informat 8: 269. doi: 10.4172/21577420.1000269

Page 3 of 6

composed of $182(45.5 \%)$ males and $218(54.5 \%)$ female pharmacy students. Most of the respondents 202 (50.2\%) were in the age 26-35 years. Most of the participants were year IV pharmacy students with response rate of $(23.8 \%)$, followed by year $\mathrm{V}$ students $(23.2 \%)$ and year I students (16.0\%), while year II (19.0\%) and year III (18.0\%) accounts for lower responders. Considering their previous educational status most were diploma in pharmacy (31.8\%) (Table 1).

\section{Disease or symptoms most frequently self-medicated}

The most frequent causes of morbidity encountered by respondents to practice self-medication were headache and fever $277(69.3 \%)$ followed by gastric pain $270(67.5 \%)$. Others like cough \& common cold, cough and chest pain, constipation, vomiting and diarrhea with respective episodes of $(46.3 \%, 46.0 \%, 30.8 \%$, and $29.5 \%)$ (Table 2$)$.

\section{Measures taken for the illnesses}

Among the respondents 109 (27.3\%) were not practiced selfmedication, $262(65.5 \%)$ were visited physicians for the illnesses encountered whereas $52(13.0 \%)$ were taken no action. Others 291 (72.8) were used self-medication from pharmacy or drug vendor without prescription, $(26.5 \%)$ used self-medications left over from prior use and self-medications from pharmacies and using borrowed medicines from friends which account for $63(15.8 \%)$ and the rest is specified in graph (Figure 1).

\begin{tabular}{|l|c|c|c|}
\hline Variables & & Frequency & Percentage \\
\hline \multirow{3}{*}{ Sex } & Male & 182 & 45.5 \\
\hline \multirow{4}{*}{ Age } & Female & 218 & 54.5 \\
\hline \multirow{4}{*}{ Year } & $18-25$ & 166 & 41.2 \\
\cline { 2 - 4 } & $26-35$ & 202 & 50.2 \\
\hline \multirow{4}{*}{$\begin{array}{l}\text { Previous } \\
\text { educational } \\
\text { status }\end{array}$} & One & 32 & 7.8 \\
\cline { 2 - 4 } & Two & 76 & 16 \\
\cline { 2 - 4 } & Fipree & 72 & 19 \\
\cline { 2 - 4 } & Four & 95 & 18 \\
\cline { 2 - 4 } & Fiploma in pharmacy & 127 & 23.8 \\
\cline { 2 - 4 } & Diploma in nurse & 63 & 13.5 \\
\cline { 2 - 4 } & Other health sciences & 79 & 15.8 \\
\cline { 2 - 4 } & Social department & 77 & 19.8 \\
\hline
\end{tabular}

Table 1: Socio demographic Information of students at Rift Valley University, Abicho campus, Addis Ababa Ethiopia, January1 ${ }^{\text {st }}$ to February $1^{\text {st }}, 2017(n=400)$.

\begin{tabular}{|l|c|c|}
\hline Disease/symptoms & Frequency & Percentage \\
\hline Fever and headache & 277 & $69.30 \%$ \\
\hline Gastric pain & 270 & $67.50 \%$ \\
\hline Cough and common cold & 185 & $46.30 \%$ \\
\hline Cough and chest pain & 184 & $46.00 \%$ \\
\hline Constipation & 123 & $30.80 \%$ \\
\hline Vomiting and diarrhea & 118 & $29.50 \%$ \\
\hline Fever and chills & 100 & $25 \%$ \\
\hline Skin symptoms & 95 & $23.80 \%$ \\
\hline Ear symptoms & 63 & $15.80 \%$ \\
\hline Eye disease & 62 & $15.50 \%$ \\
\hline Others & 28 & $7.00 \%$ \\
\hline
\end{tabular}

Table 2: Disease or symptoms most frequently self-medicated by students at Rift Valley University, Abicho campus, Addis Ababa Ethiopia, January $1^{\text {st }}$ to February ${ }^{\text {st }}$, $2017(n=400)$.
Among the respondent $46(11.5 \%)$ were included in others and they specified measures taken for the illness they encountered such as non-pharmacological treatment, traditional healers, healthy eating and exercise are some of ideas written by respondent.

\section{Drug or drug groups frequently used for self-medication}

Paracetamol was the most common medication used for selfmedication by the majority of the participants $(92.0 \%)$, followed by combinations of Paracetamol and anti-acids (71.8\%) and combinations of Paracetamol and antibiotics (66.8\%). It was also observed that $(46.8 \%)$ of the participants reported to have self-medicated with NSAIDs, others are listed in Table 3.

\section{Reasons of students for self-medications}

Among self-medicated (combinations of self-medication with visiting physicians and who used pure self-medication) the majority (81.3) has self-medicated because of non-seriousness of the illness followed by quick relief (70.3\%) and for emergency use (45.8\%). Other reasons like prior experience is (33.1) others included in Figure 2.

Among the respondent some of the students wrote their reason of self-medication which was $44(11.0 \%)$, such as, Lack of time to consult a doctor, Repetition of one type class of drug, they have already had the symptom and they know what to take, confidence on self-diagnosis and if they have history of non-responsiveness of the prescribed medication.

\section{Source of information for self-medication}

Among those self-medicated reading materials (like books) was the major source of information 225 (56.3\%) for the practice of selfmedication by participants. Advice from pharmacists, advice from physician/nurses but without prescription and personal experience

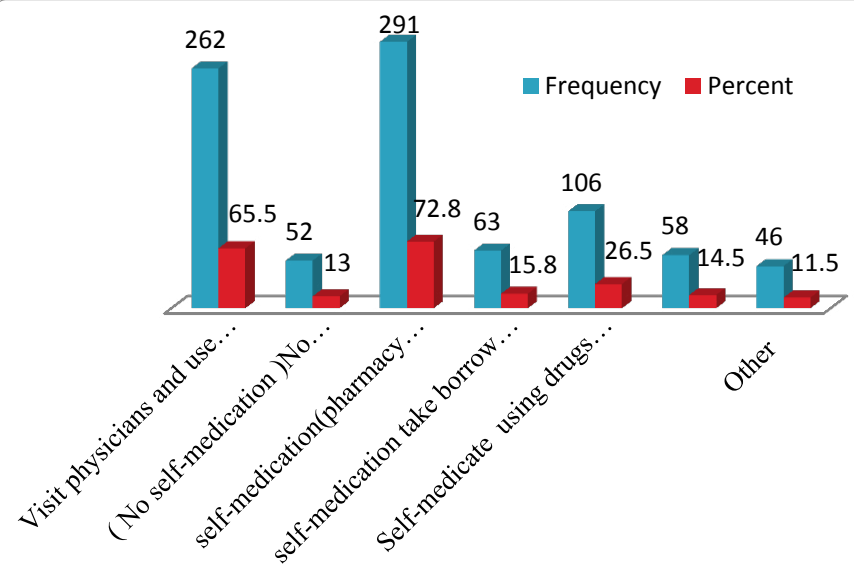

Figure 1: Measures taken for the illnesses by students at Rift Valley University, Abicho campus, Addis Ababa Ethiopia, January1 ${ }^{\text {st }}$ to February11 ${ }^{\text {st }}, 2017$ $(n=400)$.

\begin{tabular}{|l|c|c|}
\hline Drug group & Frequency & Percentage \\
\hline Paracetamol & 368 & 92 \\
\hline Antacid & 287 & 71.8 \\
\hline Antibiotics & 267 & 66.8 \\
\hline NSAIDs & 187 & 46.8 \\
\hline Vitamins & 112 & 28 \\
\hline
\end{tabular}

Table 3: Drug or drug groups frequently used for self-medication by students at Rif Valley University, Abicho campus, Addis Ababa Ethiopia, January $1^{\text {st }}$ to February $1^{\text {st }}$, $2017(n=400)$. 
Citation: Beyene A, Getachew E, Doboch A, Poulos E, Abdurahman K, et al. (2017) Knowledge, Attitude and Practice of Self Medication among Pharmacy Students of Rift Valley University, Abichu Campus, Addis Ababa, Ethiopia. J Health Med Informat 8: 269. doi: 10.4172/21577420.1000269

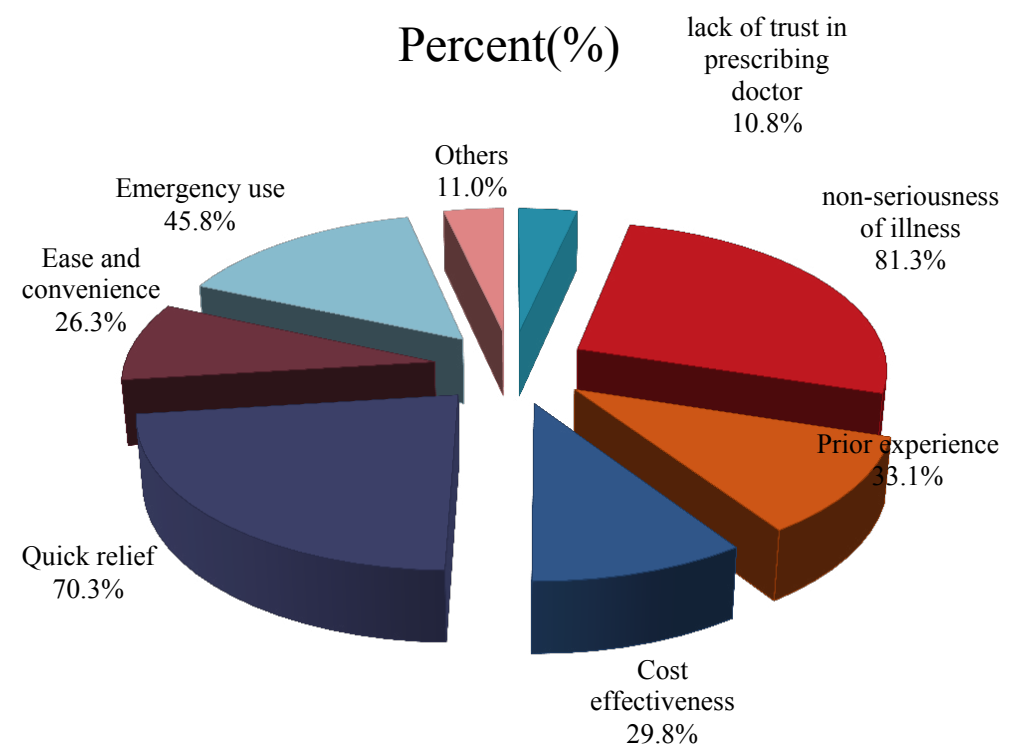

Figure 2: Reasons of students for self-medications at Rift Valley University, Abicho campus, Addis Ababa Ethiopia, and January $1^{\text {st }}$ to February ${ }^{\text {st }}, 2017$ ( $n=400$ ).

were also the other most common sources of information accounting for responses [(43.8\%), (38.8\%), and (37.3\%)] respectively. Others are specified in Table 4 .

\section{Knowledge about medication classification of OTC and prescription only drugs}

Among the respondents 189 (47.3\%) didn't know the medication classification of OTC \& prescription only drugs, even though most of the respondent stated that they knew that it may be harmful to selfmedicate, this data shows that they lacked complete knowledge. 165 (41.3\%) has information about the medication classification of OTC \& prescription only drugs. Others 46 (11.5) has no information about medication classification of OTC \& prescription only drugs and it is also specified in Table 5 .

\section{Attitude of students towards self-medication practice}

Data regarding attitude toward self-medication was collected from 400 students, including those who did not practiced self-medication, the majority of students $310(77.5 \%)$ agreed on the practice of self-medication is part of self-care. On the other hand, $90(22.5 \%)$ students disagreed with this practice, when asked about the influence of pharmacists on their attitude towards self-medication; more 304 $(76.0 \%)$ felt that the pharmacists are a good source of information for minor illness, and 96 (24.0\%) disagreed. Most around 60 (15.0\%) of respondents had agreed that self-medication would be harmful if taken without proper knowledge of disease and drug. 149 (37.3\%) of respondents had agreed that self-medication is acceptable for medical students. Most pharmacy students believe that health science students have good ability to practice self-medication (Table 6).

\section{Discussion}

Self-medication is practiced throughout the world in the general population even if the reasons may vary. The practice is expected to be higher in developing countries like Ethiopia this may be due to limited number of health care facilities available to the public. Self-medication is also expected to be even more practiced among health science students, who differed from the general population because they were exposed

\begin{tabular}{|l|c|c|}
\hline Source of information & Frequency & Percentage \\
\hline Reading materials and medical books & 225 & 56.3 \\
\hline Advice from pharmacists & 175 & 43.8 \\
\hline $\begin{array}{l}\text { Advice from physician/nurse but without } \\
\text { prescriptions }\end{array}$ & 155 & 38.8 \\
\hline My own experience & 149 & 37.3 \\
\hline Others (internet and advertisement) & 77 & 19.3 \\
\hline Advice from classmate friend & 60 & 15 \\
\hline Advice from traditional healers & 39 & 9.8 \\
\hline
\end{tabular}

Table 4: Source of information for self-medication used by the students at Rift Valley University, Abicho campus, Addis Ababa Ethiopia, January $1^{\text {st }}$ to February ${ }^{\text {st }}$, $2017(n=400)$.

\begin{tabular}{|l|c|c|c|}
\hline $\begin{array}{l}\text { Do you know the medication } \\
\text { classification of OTC and } \\
\text { prescription only drugs? }\end{array}$ & No & Yes & $\begin{array}{c}\text { I don't have } \\
\text { information }\end{array}$ \\
\cline { 2 - 4 } & $189(47.3 \%)$ & $165(41.3 \%)$ & $46(11.5 \%)$ \\
\hline
\end{tabular}

Table 5: Knowledge about medication classification of students at Rift Valley University, Abicho campus, Addis Ababa Ethiopia, January $1^{\text {st }}$ to February $1^{\text {st }}, 2017$ $(n=400)$.

\begin{tabular}{|l|c|c|}
\hline Attitude & Agree & Disagree \\
\hline Self-medication is part of self-care & $310(77.5 \%)$ & $90(22.5 \%)$ \\
\hline $\begin{array}{l}\text { Pharmacists are good source of information for } \\
\text { minor medical problems }\end{array}$ & $304(76.0 \%)$ & $96(24.0 \%)$ \\
\hline $\begin{array}{l}\text { The course of medicines should be complete } \\
\text { although the symptoms subside }\end{array}$ & $230(57.5 \%)$ & $170(42.5 \%)$ \\
\hline $\begin{array}{l}\text { Health science students have good ability to } \\
\text { treat symptoms }\end{array}$ & $215(53.7 \%)$ & $185(46.25 \%)$ \\
\hline $\begin{array}{l}\text { Self-medication is acceptable for medical } \\
\text { students }\end{array}$ & $149(37.3 \%)$ & $251(62.8 \%)$ \\
\hline Not acceptable at all and it would be harmful & $60(15.0 \%)$ & $340(85.0 \%)$ \\
\hline
\end{tabular}

Table 6: Attitude of students towards self-medication practice of students at Rift Valley University, Abicho campus, Addis Ababa Ethiopia, January $1^{\text {st }}$ to February $1^{\text {st }}$ $2017(n=400)$.

to knowledge about diseases and drugs, so they might be expected to behave differently [14]. Self-medication practice is prevalent in Ethiopia and varies in different populations and regions of the country [15]. This research was done to assess self-medication attitude and practice among pharmacy students, in Rift Valley University. 
Based on demographic characteristics of our study, there were 182 (45.5\%) males and 218 (54.5\%) female pharmacy students. Most of the respondents $202(50.2 \%)$ were in the age 26 - 35 years; this is because of that our study includes all extension, weekend and regular students. Our finding is in agreement with the study conducted in Mekelle where $112(75.6 \%)$ were female student, and the mean age of the respondent was $26(17.56 \%)$ [16]. But, when we compare this result with other similar study done in south India the mean age among the participant students was a bit higher in the south Indian study (28\%) whereas female were higher similar to our study [17].

In our study many of the participants were Year-IV pharmacy students with a response rate of $23.8 \%$, followed by year-V students (23.2\%) and year-I students (16.0\%), while year-II (19.0\%) and year-III (18.0\%) accounts for lower response rates. Considering their previous educational status most of the respondents were diploma in pharmacy (31.8\%). This finding was also in line with the study conducted in Mekelle where most of the participant was year 4 pharmacy students [16].

The current study shows that among the respondents $109(27.3 \%)$ has not practiced self-medication, $262(65.5 \%)$ has visited physicians for the illnesses encountered whereas $52(13.0 \%)$ has taken no action. Others 291 (72.8) used pure self-medication from pharmacy or drug vendor without prescription, (26.5\%) used self-medications left over from prior use and 63 (15.8\%) used self-medications from borrowed medicines from friends. According to another study made among medical students in coastal south India, the prevalence of pure selfmedication was $78.6 \%$. And the similar study in Nepal revealed $84 \%$ of prevalence of self-medication [18].

On study from Ethiopia reported that self-medication up to $95 \%$ among college students in Southwest Ethiopia [19]. Another study conducted in Iran (Isfahan university pharmacy student) demonstrates that about $84.9 \%$ of students in Isfahan University of pharmacy students self-medicate [20]. While a comparative study of selfmedication practice among medical \& engineering students in a private university in north India indicates that out of the 316 medical students $232(73.4 \%)$ were practicing self-medication [21]. When compared to two studies done on health science students in Ethiopia, study in Gondar 130 of the 213 students $(61.3 \%)$ had practiced self-medication during the two months period prior to the study [22]. The Mekelle study reported out of 148 respondents, 93 respondents were practicing self-medication [16].

The current study has found that fever and headache 277 (69.3), combination of fever/headache, and Gastric pain 270 (67.5) were reported to be the most frequent diseases for the practice of selfmedication. The study done in Palestine reported that headache, sore throat, flu, and dysmenorrhea were the most common ailments for which respondents seek self-medication [23]. When we compare this result the west Bengal, cough and common cold were reported by 94 students (35.21\%) followed by diarrhea (68 students) (25.47\%), fever (42 students) (15.73\%), headache (40 students) (14.98\%) and pain abdomen due to heartburn/peptic ulcer (23 students) (8.61\%) [24]. The study done in Gondar reported that fever and headache were the most frequently self-medicated enquiring illness, while gastrointestinal tract disease and cough and common cold were the second and the third most common disease treated by self-medication with the prevalence of 55 (24.8\%), 51 (23.9\%), and 28 (13.2\%) respectively [22]. However, in studies reported from Iran, Mozambique, Pakistan, and Egypt analgesics were the most common group indicated for self-medication and fever was the most common illness seeking self-medication.
The present study identified that Paracetamol was the most common medication used for self-medication by the majority of the participants $(92.0 \%)$, followed by combinations of paracetamol and anti-acids (71.8\%) and combinations of paracetamol and antibiotics (66.8\%). It was also observed that $(46.8 \%)$ of the participants reported to have self-medication with NSAIDs. This data was similar to the study done in Gondar University where among the respondent 38 (46.3) of 82 student were using paracetamol, and other were using another analgesics 20 (24.4\%) followed by anti-acid 10 (12.2\%) [22]. However a study conducted in Malaysia showed that (50.3\%) supplements/ vitamins were the most frequently used OTC medications followed by painkillers (27\%), flu/cough remedies [25]. The study done in south India reported that the classes of drugs that were commonly used were, antipyretics $(71 \%)$, analgesics $(65 \%)$, antihistamines $(37 \%)$ and antibiotics (34\%). According to the study done in Iran most of the drugs used were cold or flu drugs and painkillers [20]

Studies reported that the most common reason for self-medication is treatment of minor illness [25]. The study done in south India denoted that the most common reasons were minor ailments $(82 \%)$ and lack of time to consult a doctor (11\%). The common reason for self-medication in the Indian study among medical students was confidence in self-diagnosis $(8.5 \%)$, it also reported that medical students self-medicate themselves any circumstances of minor ailments [17], when we compared with our study the majority (81.3) has selfmedicated because of non-seriousness of the illness followed by quick relief $(70.3 \%)$ and for emergency use (45.8\%). Other reason like prior experience $(33.1 \%)$ was also reported. Similar study done in Palestine showed that majority of respondents practiced self-medication because the ailments they encounter were simple and previous experiences [23]. The study in Gondar reported the reasons for self-medication including prior experience (79\%), mildness of illness (80.2\%), financial constraint, educational level or knowledge about drugs.

In our study the main source of information while self-medication was reading material (56.3\%) followed by advice from pharmacist (43.8\%), and advice from physician/nurses without prescription $(38.8 \%)$. When we see study done in south India the study group cited their source of information for self- medication in most cases as textbooks (39\%) and seniors or classmates (38\%) [18]. Similarly study in Gondar the major information source for most of those who practiced self-medication was reading material (30.5) which accounts highest number of student and the least is advice from traditional healers (3.7\%) [22]. The latter is the similar to our study.

In a study done in south coastal India $47 \%$ of the participants agreed that self-medication was part of self-care. In our study the majority of students $310(77.5 \%)$ agreed on the practice of self-medication is part of self-care. On the other hand, 90 (22.5\%) students disagreed with this practice. Study in Gondar among the total respondent 55.5\% agreed on self-medication practice and $44.5 \%$ disagreed on this practice [22]. In most of studies respondent had a positive attitude favouring selfmedication.

Regarding knowledge of student in our study, 189 (47.3\%) didn't know the medication classification of OTC \& prescription only drugs whereas $165(41.3 \%)$ reported that they had information about the medication classification. In the UAE study the most prevalent respondents were aware of bacterial resistance and the concept of rational drug use and have information about medication [4]. Study in Malaysian About $82 \%$ of the respondents stated that their level of knowledge regarding OTC medications was moderate to low. Eighty one percent of the participants said that they would stop using the OTC 
Citation: Beyene A, Getachew E, Doboch A, Poulos E, Abdurahman K, et al. (2017) Knowledge, Attitude and Practice of Self Medication among Pharmacy Students of Rift Valley University, Abichu Campus, Addis Ababa, Ethiopia. J Health Med Informat 8: 269. doi: 10.4172/21577420.1000269

drug if it did not work within the proposed time frame, while a small number of them would increase (7\%) or decrease (5\%) the dose [25].

\section{Conclusion and Recommendation}

A majority number of students were identified to practice selfmedication and half of the students had no knowledge about OTC and prescriptions only drugs. Prevalence of self-medication increases as year of study increases this may be due to increased study exposure to diseases and medications. Student attitude towards self-medication significant number of student agreed on Self-medication is part of self-care. Hence, college students should be aware the consequence of improper use of medications leading to drug resistance, toxicity, and increased side effects. It is also worthy to note here that our participants belong to the current generation of society and if the prevalence of selfmedication is so high in people who are aware of its dangers, then the prevalence in the rest of the people may be even more serious cause for concern. Although the self-medication practice is inevitable; drug authorities and health professionals need to educate students about the pros and cons of self-medication and also, strong policies should be applied prohibiting the supply of medicines without a valid prescription.

\section{Acknowledgement}

We praise God-the almighty! Thank you for giving us one additional day. Thank you all Rift Valley pharmacy students and thank you all the Rift Valley University, Abichu Campus staff.

\section{Authors' Contribution}

This work was carried out in collaboration with the following authors. 'Author $E G, A D, E P$ and KA' collected the data, performed the statistical analysis, wrote the proposal, and wrote the first draft of the manuscript. 'Author AB' designed the study, managed the analyses of the study and managed the literature searches. 'Autho MA' managed the analyses of the study and managed the literature searches. All authors read and approved the final manuscript.

\section{Conflict of Interest}

Authors declare that there is no conflict of interest regarding publication of this manuscript.

\section{References}

1. Montastruc J, Montastruc JL, Bagheri H, Geraud T, Lapeyre-Mestre M (1996) Pharmacovigilance of self-medication. Therapie 52: 105-110.

2. Syed N (2015) Self-medication amongst University Students of Karachi: Prevalence, knowledge and attitudes. Studen Corn 20: 120-210.

3. Lukovic JA, Miletic V, Pekmezovic T, Trajkovic G, Ratkovic N, et al. (2016) Self-Medication Practices and Risk Factors for Self-Medication among Medical Students in Belgrade. PLoS ONE 2: 240-253.

4. Suleiman I, Sharif L, Rubian S (2015) Self-medication practice among pharmacists in UAE. Pharmacol Pharm 6: 428-435.

5. Awad Al, Eltayeb IB, Capps PA (2006) Self-medication practices in Khartoum state, Sudan. Eur J Clin Pharmacol 62: 317

6. Gyawali S, Shankar PR, Poudel PP, Saha A (2015) Knowledge, attitude and practice of self-medication among basic science undergraduate medical students in a medical school in Western Nepal. J Clin Diagn Res 2: 1-2.

7. The World Health Organization (2015), Guidelines for the regulatory assessment of Medicinal product for use in self-medication.
8. EI Ezz NF, Ez-Elarab HS (2011) Knowledge, attitude and practice of medical students towards self-medication at Ain Shams University, Egypt. J Prev Med Hyg 1: 183-189.

9. Hughes CM, McElnay JC, Fleming GF (2001) Benefits and risks of selfmedication. Drug Saf 24: 1027-1037.

10. Hardon A, Van der Geest S (1987) Hazards of self-medication. Wor Healt Foru

11. James H, Handu SS, Khaja KA, Otoom S, Sequeira R (2016) Evaluation of the knowledge, attitude and practice of self-medication among first-year medica students. Med Princ Pract 3: 244-300.

12. Raj K, Sujaja S (2015) Knowledge, attitude, practice of self-medication among medical students. IOSR-JNHS 4: 89-96.

13. Michelle $P$ (2011) An examination of awareness of over-the-counter no steroidal anti-inflammatory drugs and adverse events. UMI 9: 121-125.

14. Ayalew MB (2017) Self-medication practices in Ethiopia: a systematic review. Pat Pref Adhe 11: 401-413.

15. Belachew G, DiribaG (2011) Self-medication practices among health science students in Mekelle. J App Pharm Sci 1: 183-189.

16. Badiger S, Kundapur R, Jain A, Kumar A, Pattanshetty S, et al. (2010) Selfmedication patterns among medical students in South India. Aust Med $\mathrm{J} 1$ : 183-189.

17. Nithin K, Bhaskarn $U$ (2016) Perception and practice of self -medication among medical students in coastal south India. IJEIMS 8: 231-235.

18. Angamo MT, Wabe NT (2012) Knowledge, attitude and practice of selfmedication in Southwest Ethiopia. Int J Pharm Sci Res 3: 1001-1005.

19. Asiyeh P, Firoozeh M (2016) Self-medication among students in Isfahan University of Medical Sciences based on Health Belief Model. J Educ Health Promot 10: 190-220.

20. Parakh R, Sharma N (2015) A comparative study of self -medication practice among medical and engineering students in a private university, in north India.

21. Abay SM, Amelo W (2010) Assessment of Self-Medication Practices among Medical, Pharmacy, and Health Science Students in Gondar University. J Young Pharm 2: 1-5.

22. Ansam F, Sawalha T (2010) Magnitude and factors of self-medication on pharmacy students. Palestin 3: 141-160

23. Banerjee I, Bhadury T (2012) Self-medication practice among undergraduate medical students in a tertiary care medical college, West Bengal. J Pos Grad Med 4: 127-131.

24. Mohamed Azhar MI, Gunasekaran K, Kadirvelu A, Gurtu S, Sadasivan S (2015) Self-medication: awareness and attitude among Malaysian urban population. IJCRIMPH 2: 500-560.

25. Nithin K, Bhaskarn U (2013) Perception and practice of self -medication among medical students in coastal south India. IJEIMS 8: 1-5. 